Thorax (1975), 30, 293.

\title{
Variability in the size of airspaces in normal human lungs as estimated by aerosols
}

\author{
N.L.LA P P, J.L. H A N K I N O N, H. A M A N D U , \\ a n d E. D. P A L M E S
}

Appalachian Laboratory for Occupational Respiratory Diseases, National Institute for Occupational Safety and Health, Public Health Service, Center for Disease Control, Department of Health, Education, and Welfare, and Department of Medicine, West Virginia University Medical Center, Morgantown, West Virginia 26505, and Institute of Environmental Medicine, New York University Medical Center, New York, New York 10016, USA

\begin{abstract}
Lapp, N. L., Hankinson, J. L., Amandus, H., and Palmes, E. D. (1975). Thorax, 30, 293-299. Variability in the size of airspaces in normal human lungs as estimated by aerosols. Measurement of persistence, expressed as half-life ( $\left.t \frac{1}{2}\right)$, of a monodisperse aerosol during breath holding was interpreted as an indirect estimate of the size of intrapulmonary airspaces in healthy subjects. Within subject variation of $t \frac{1}{2}$ measured over a period of nearly two years was small (coefficient of variation $7 \cdot 7$ to $11.5 \%$ ). Mean effective airspace diameters were calculated from the aerosol t $\frac{1}{2}$ values using the settling term from the equation of Landahl (1950). Calculated mean airspace diameters ranged from 0.30 to $0.79 \mathrm{~mm}$ for 36 males and from 0.40 to $0.62 \mathrm{~mm}$ for 12 females. Airspace diameters correlated poorly with age, height, weight, and lung volumes. These results suggest marked differences in airways geometry in subjects with similar heights and lung volumes.
\end{abstract}

Previous work has shown that the persistence expressed as half-life (t $\left.\frac{1}{2}\right)$ of aerosol in the human respiratory tract during breath holding can be interpreted as an indirect method of estimating the size of the airspaces containing the aerosol during breath holding (Palmes, Altshuler, and Nelson, 1967; Palmes, 1973; Palmes et al., 1973). Efforts have also been made to employ aerosols in this manner as a diagnostic test for emphysema. Preliminary studies (Palmes et al., 1971) in this area were encouraging, and it was decided to employ the same apparatus and procedures on a larger population of normal subjects in order $(a)$ to establish reproducibility of the aerosol results on individuals tested at various times, and $(b)$ to determine the range of half-lives in a normal population.

It was also planned to measure a number of pulmonary function indices that incorporate estimates of lung size and volume as well as can be determined during life, in order to see which, if any, of these correlated with the aerosol half-lives.

There has been relatively little work on inhalation of homogeneous aerosols by man, and most of this has been done under steady state breathing conditions in order to estimate total or regional deposition as a function of particle size. Measurement of aerosol persistence during breath holding may be interpreted as an index of the lung airspace sizes. The rationale is that a particle, having been transported into the lung, will remain airborne until it has traversed a distance necessary to strike a wall. If the particles are all of the same size the mean displacement per unit time by a combination of Brownian motion and sedimentation is constant. It follows, therefore, that the larger the airspace the longer the time required to strike a wall. The effect of lung volume and indirectly the size of the airspace on aerosol persistence was demonstrated in three normal subjects by measuring the rate of disappearance when the breath was held at several different volumes (Palmes et al., 1971); the half-life decreased linearly with lung volume.

\section{METHODS $^{1}$}

Procedures for generation, characterization, and breathing of aerosols have been described in detail

${ }^{1}$ Mention of commercial products or brand names does not constitute endorsement by the Public Health Service 
elsewhere (Palmes and Wang, 1971). Briefly, a homogeneous aerosol of triphenylphosphate at about $10^{5}$ particles per millilitre is inhaled as part of a respiratory manoeuvre programmed in the breathing apparatus as shown in Figure 1. The total manoeuvre involves several normal breaths followed by an inhalation to total lung capacity (TLC) at which point the programmed sequence begins. The subject exhales 1.2 litres, inhales 1.0 litre, holds his breath for 0-30 seconds, and then exhales 2 litres. Inhalation and exhalation concentrations are measured by light scattering, and the quantity of aerosol exhaled is divided by the quantity inhaled to give the persistence for the time the breath was held. Since the persistence decreases exponentially with the time of breath holding (Palmes et al., 1967), it can be expressed in terms of a half-life.

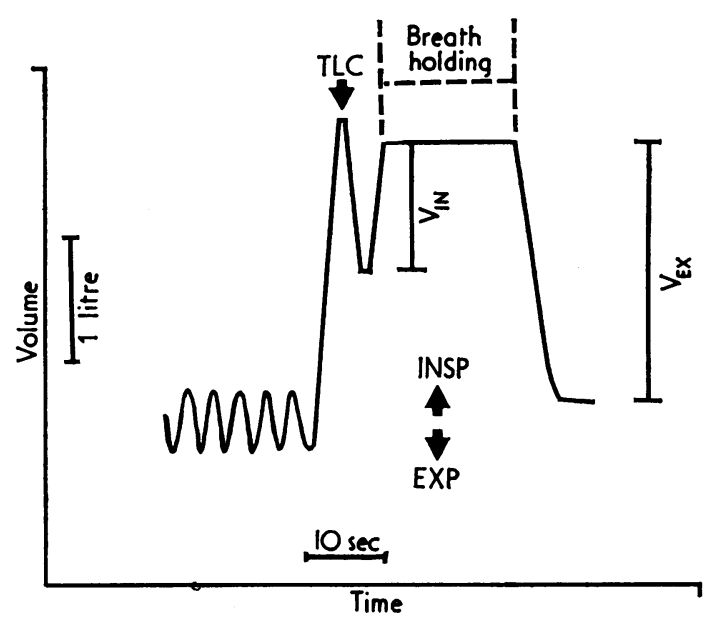

FIG. 1. Typical aerosol inhalation and breath holding manoeuvre. (Reprinted by permission of the editor from: Palmes, $E$. $D$. and Wang, C. S. (1971). American Industrial Hygiene Association Journal, 32, 43.)

This half-life can be used to calculate for a tubular model the average or 'effective' diameter of the space in which the aerosol is confined. The rationale is that particles randomly distributed in randomly orientated tubes of infinite length, as treated by Landahl (1950), will be deposited at an exponential rate, the exponent being determined by the diameter of the tubing and by the physical properties of the particles. As discussed in an earlier publication (Palmes et al., 1973), the equation derived from Landahl can be simplified in dealing with triphenylphosphate aerosol particles $\stackrel{\overrightarrow{5}}{\stackrel{5}{9}}$ of approximately 0.55 micra diameter. The persistence of the aerosol can then be based com- $\frac{\bar{O}}{\bar{D}}$ pletely on the sedimentation rate of particles $\underset{\oplus}{\vec{\sigma}}$ during breath holding. The justification for dis- $\stackrel{\varnothing}{\varnothing}$ regarding Brownian motion is derived from the is work of Wang, Altshuler, and Palmes (1968), who $\vec{\circ}$ showed that for particles suspended between parallel plates the larger of the separate effects of $\vec{\omega}$ settling and Brownian motion is generally a better $\stackrel{\circ}{F}$ approximation than that which treats the separate $\vec{x}$ probabilities of deposition independently. In the $\dot{\omega}$ present studies the simplified equation is:

Airspace diameter $=0.027 \mathrm{~mm} / \mathrm{sec} \times \mathrm{t}_{2}^{\frac{1}{2}}(\mathrm{sec}) \quad$ i The constant $0.027 \mathrm{~mm} / \mathrm{sec}$ is the rate of gravita- $\mathscr{E}$ tional settling for the subject particles in air; thus $\frac{\text { ㅇ }}{3}$ the half-life gives a direct index of the size of the airspaces. This size is defined as that diameter $\subseteq$ tubing which, if of infinite length and randomly $\overparen{D}$ orientated, would show the same aerosol persis- $\vec{\theta}$ tence or half-life as that observed in the human or subject.

It should be noted that with a 1-litre inhalation most of the aerosol should still be airborne and located within the small airspaces within the parenchyma during breath holding since the $\frac{\circ}{\Phi}$ 1 -litre breath is considerably larger than the ana- $\frac{Q}{\not 2}$ tomical deadspace. Each sequence involves 6 to 10 breaths, breath holding ranging from 0 to 303 seconds. The results for the series of breaths were used to determine the slope of the persistence curve by a least squares procedure. It was then possible to determine the half-life, intercept for zero breath holding time, and the $95 \%$ confidence $\stackrel{x}{0}$ limits for the half-life.

The study population includes 36 men and 12. women. All were members of the professional and $\frac{0}{3}$ technical staff of the Appalachian Laboratory, the West Virginia University Medical Center, or New York University Medical Center. Twenty-two of $\frac{D}{0}$ the men and eight of the women had never smoked. Twelve men were former smokers. Two $\mathrm{N}$ men and four women were cigarette smokers at $N$ the time of the study.

Spirometry was performed using a high-fidelity $\omega^{\omega}$ waterless electronic spirometer (Ohio Medical Products, Madison, Wisconsin, Model 800) equipped with temperature probe (Yellow Springs $\stackrel{\circledast}{\circledR}$ Instrument Co., Yellow Springs, Ohio, Model 405) and time-pulse generator (Hankinson and 0 Lapp, 1970). Total lung capacity and airways $\overrightarrow{\mathbb{D}}$ resistance were measured in a constant volume $\frac{\rho}{\mathbb{D}}$ body plethysmograph (Warren E. Collins, Inc., ㅇ Braintree, Mass.) using the methods of Dubois et al. (1956a) and Dubois, Botelho, and Comroe 8 
(1956b). The predicted values for total lung capacity were calculated from the short formulae of Needham, Rogan, and McDonald (1954), and those for forced vital capacity were obtained from Kory et al. (1961) and Kory, Smith, and Callahan (1966).

Diffusing capacity for carbon monoxide was measured by the single breath technique (Ogilvie et al., 1957) modified by using residual volume obtained in the plethysmograph and analysing the gases in a gas chromatograph (Beckman Co., Fullerton, California, Model GC5A). Values obtained in 20 healthy men and 30 healthy women subjects in the ALFORD laboratory were used to predict the normal diffusing capacity in these subjects (Seaton, 1972; Seaton, Lapp, and Morgan, 1972).

Anatomical deadspace at functional residual capacity was estimated in 21 of the men and 11 of the women by the method of Fowler (1948).

\section{RESULTS}

Values for the half-life of aerosol persistence obtained in seven subjects (five men and two women) measured on at least five different occasions over a period of nearly two years are shown in Table $I$. The within subject variation for $t \frac{1}{2}$ was relatively constant, as indicated by the coefficient of variation. $((\mathrm{SD} /$ Mean $) \times 100)$ which ranged from $7.7 \%$ to $11 \cdot 5 \%$.

Values for the various indices of pulmonary function and $t^{\frac{1}{2}}$ of aerosol persistence within the respiratory airspaces during breath holding for the study subjects are available from the authors upon request. The mean values, and standard deviations for the pulmonary function indices, aerosol $t \frac{1}{2}$, and average airspace diameter are grouped by sex and smoking status in Table II. The women were shorter, not as heavy, and on average somewhat younger than the men. Within the male group the nonsmokers and current smokers were also shorter, younger, and lighter than their exsmoking counterparts.
Total lung capacity expressed as a percent of predicted value averaged about $90 \%$ of predicted for all groups. However, there were no differences between the subjects in each of the smoking categories in regard to TLC.

Forced vital capacity (FVC), which in nonobstructed subjects is approximately the same as vital capacity, averaged slightly greater than predicted overall, but there were no significant differences between the mean values for each smoking category.

Diffusing capacity for carbon monoxide (DLCo) averaged about $100 \%$ of the predicted value for the men but averaged approximately $90 \%$ for the women.

In those subjects in whom it was measured, the mean values for anatomical deadspace (VD) were found to be somewhat lower than the expected value of approximately $1 \mathrm{ml}$ per pound $(0.45 \mathrm{~kg})$ of body weight (Radford, 1955).

It is well known that lung volumes tend to be reasonably closely related to height and that airways resistance and diffusing capacity for carbon monoxide are largely related to lung volume. We therefore sought similar relationships of estimated airspace diameters to height and lung volumes. Among the male subjects correlation coefficients between estimated airspace diameters and height, age, TLC, FVC, DLCO, and VD, were $r=-0.46$, $\mathrm{r}=-0.46, \quad \mathrm{r}=-0.38, \mathrm{r}=-0.25, \mathrm{r}=-0.14$, and $\mathrm{r}=-0 \cdot 40$, respectively. The highest correlation coefficients found among the female subjects were between estimated airspace diameters and FVC $(r=0.74)$ and VD $(r=0.71)$. The correlation coefficients between estimated airspace diameters and height, age, TLC, and DLCo for the women were $\mathrm{r}=0.20, \mathrm{r}=-0.21, \mathrm{r}=0.50$, and $\mathrm{r}=0 \cdot 13$, respectively.

The mean calculated airspace diameters for nonsmoking males were similar to those obtained for both nonsmoking and smoking females; whereas, the values for exsmoking males were significantly larger. These differences might be a consequence of the difference in age between the

T A B L E I

REPRODUCIBILITY OF MEASUREMENT OF HALF-LIFE

\begin{tabular}{|c|c|c|c|c|c|c|c|c|c|}
\hline \multirow{2}{*}{$\begin{array}{c}\begin{array}{c}\text { Subject } \\
\text { No. }\end{array} \\
6 \\
16 \\
18 \\
22 \\
31 \\
39 \\
44\end{array}$} & \multicolumn{6}{|c|}{ Half-life } & \multirow{2}{*}{$\begin{array}{c}\begin{array}{c}\text { Mean } \\
\text { X }\end{array} \\
18 \cdot 5 \\
23 \cdot 7 \\
11 \cdot 1 \\
21 \cdot 7 \\
26 \cdot 3 \\
21 \cdot 6 \\
20 \cdot 8\end{array}$} & \multirow{2}{*}{$\begin{array}{c}\begin{array}{c}\text { Standard } \\
\text { Deviation } \\
\text { S }\end{array} \\
2 \cdot 13 \\
2.62 \\
0.86 \\
2 \cdot 13 \\
2 \cdot 11 \\
2.49 \\
1.85\end{array}$} & \multirow{2}{*}{$\begin{array}{c}\begin{array}{c}\text { Coefficient } \\
\text { of Variation } \\
\text { S/X }\end{array} \\
11 \cdot 5 \\
11 \cdot 0 \\
7.7 \\
9.8 \\
8.0 \\
11.5 \\
8.9\end{array}$} \\
\hline & $\begin{array}{l}19 \cdot 4 \\
22.9 \\
10 \cdot 0 \\
20 \cdot 4 \\
26 \cdot 1 \\
20 \cdot 3 \\
18.9\end{array}$ & $\begin{array}{l}15 \cdot 8 \\
22 \cdot 9 \\
12 \cdot 2 \\
19 \cdot 9 \\
24 \cdot 3 \\
19 \cdot 9 \\
21 \cdot 2\end{array}$ & $\begin{array}{l}17 \cdot 0 \\
22 \cdot 0 \\
11 \cdot 3 \\
23 \cdot 4 \\
29 \cdot 4 \\
19 \cdot 6 \\
19.6\end{array}$ & $\begin{array}{l}21 \cdot 2 \\
22 \cdot 2 \\
10 \cdot 6 \\
21 \cdot 3 \\
25 \cdot 3 \\
22 \cdot 6 \\
20 \cdot 4\end{array}$ & $\begin{array}{l}19 \cdot 2 \\
28 \cdot 3 \\
11 \cdot 6 \\
25 \cdot 2 \\
24 \cdot 5 \\
25 \cdot 5 \\
23 \cdot 7\end{array}$ & $\begin{array}{l}\text { 二 } \\
2 \overline{2} \cdot 1 \\
28 \cdot 4 \\
\text { - }\end{array}$ & & & \\
\hline
\end{tabular}


T A B L E I I

SUMMARY STATISTICS

\begin{tabular}{|c|c|c|c|c|c|c|c|c|c|c|c|}
\hline Subject & $\begin{array}{l}\text { Height } \\
\text { (in.) }\end{array}$ & $\begin{array}{c}\text { Weight } \\
\text { (lb.) }\end{array}$ & $\begin{array}{c}\text { Age } \\
\text { (yr.) }\end{array}$ & $\begin{array}{l}\text { TLC } \\
\% \text { pred. }\end{array}$ & $\begin{array}{l}\text { FVC } \\
\% \text { pred. }\end{array}$ & $\begin{array}{l}\text { Dico } \\
\% \text { pred. }\end{array}$ & $\begin{array}{r}\mathbf{R A W}^{\mathbf{2}} \\
\left(\mathbf{c m H} \mathbf{c}_{2} \mathbf{O}\right. \\
1 / \mathrm{sec})\end{array}$ & $\begin{array}{l}\mathrm{TGV}^{\mathbf{2}} \\
\text { (litres) }\end{array}$ & $\begin{array}{c}\mathrm{VD}^{3} \\
\text { (ml.) }\end{array}$ & $\begin{array}{c}\text { Half-life } \\
(\mathrm{sec} .)\end{array}$ & $\begin{array}{c}\text { Airspace } \\
\text { Diam } \\
(\mathrm{mm} .)\end{array}$ \\
\hline $\begin{array}{c}\text { Males, all } \\
n \\
\overline{\mathbf{x}} \\
\mathbf{S D}\end{array}$ & $\begin{array}{l}36 \\
69.9 \\
1.9\end{array}$ & $\begin{array}{r}36 \\
165.9 \\
19.8\end{array}$ & $\begin{array}{l}36 \\
32.9 \\
10 \cdot 7\end{array}$ & $\begin{array}{l}36 \\
89 \cdot 4 \\
11 \cdot 0\end{array}$ & $\begin{array}{c}36 \\
105.5 \\
12.6\end{array}$ & $\begin{array}{r}31 \\
101 \cdot 3 \\
10.4\end{array}$ & $\begin{array}{c}36 \\
1.58 \\
0.44\end{array}$ & $\begin{array}{c}36 \\
3.92 \\
0.69\end{array}$ & $\begin{array}{r}21 \\
141.8 \\
27.0\end{array}$ & $\begin{array}{l}36 \\
20 \cdot 0 \\
4.4\end{array}$ & $\begin{array}{c}36 \\
0.55 \\
0.12\end{array}$ \\
\hline $\begin{array}{l}\text { Nonsmokers } \\
\text { n } \\
\overline{\mathrm{x}} \\
\mathbf{S D}\end{array}$ & \begin{tabular}{|l}
22 \\
69.8 \\
1.82
\end{tabular} & $\begin{array}{l}22 \\
162.2 \\
18 \cdot 8\end{array}$ & $\begin{array}{l}22 \\
29 \cdot 84 \\
8 \cdot 2\end{array}$ & $\begin{array}{l}22 \\
89.4 \\
13.4\end{array}$ & $\begin{array}{c}22 \\
106 \cdot 2 \\
14 \cdot 1\end{array}$ & $\begin{array}{r}21 \\
101.0 \\
10.9\end{array}$ & $\begin{array}{l}22 \\
1.48 \\
0.37\end{array}$ & $\begin{array}{r}22 \\
3.86 \\
0.72\end{array}$ & $\begin{array}{r}15 \\
141.0 \\
27.7\end{array}$ & $\begin{array}{l}22 \\
18 \cdot 8^{4} \\
3 \cdot 9\end{array}$ & $\begin{array}{l}22 \\
0.51^{4} \\
0.11\end{array}$ \\
\hline $\begin{array}{l}\text { Exsmokers } \\
\text { n } \\
\overline{\mathbf{x}} \\
\text { SD }\end{array}$ & $\begin{array}{l}12 \\
70 \cdot 1 \\
2 \cdot 20\end{array}$ & $\begin{array}{c}12 \\
175.7 \\
18 \cdot 8\end{array}$ & $\begin{array}{l}12 \\
40 \cdot 0^{4} \\
12 \cdot 4\end{array}$ & $\begin{array}{l}12 \\
90.5 \\
5.9\end{array}$ & $\begin{array}{c}12 \\
105.0 \\
10.8\end{array}$ & $\begin{array}{r}9 \\
103 \cdot 0 \\
9.5\end{array}$ & $\begin{array}{c}12 \\
1.72 \\
0.52\end{array}$ & $\begin{array}{r}12 \\
4.05 \\
0.69\end{array}$ & $\begin{array}{c}5 \\
146 \cdot 0 \\
30.0\end{array}$ & $\begin{array}{l}12 \\
22 \cdot 2^{4} \\
4 \cdot 8\end{array}$ & $\begin{array}{c}12 \\
0.614 \\
0.13\end{array}$ \\
\hline $\begin{array}{c}n \\
\overline{\mathbf{x}} \\
\mathbf{S D}\end{array}$ & $\underset{69 \cdot 8}{2}$ & $\stackrel{2}{148.5}$ & $\stackrel{25 \cdot 0}{-}$ & $82 \cdot 5$ & $100 \cdot 5$ & $91 \cdot 0$ & $\begin{array}{l}2 \\
1.84\end{array}$ & $\begin{array}{l}2 \\
3 \cdot 65 \\
-\end{array}$ & $133 \cdot 0$ & $20 \cdot 6$ & $\begin{array}{l}2 \\
0.56\end{array}$ \\
\hline $\begin{array}{l}\text { Females, all } \\
\text { n } \\
\text { 齐 } \\
\text { Nonsmokers }\end{array}$ & $\begin{array}{l}12 \\
64 \cdot 4 \\
1 \cdot 5\end{array}$ & $\begin{array}{l}12 \\
121.8 \\
14.1\end{array}$ & $\begin{array}{l}12 \\
25.8 \\
8.6\end{array}$ & $\begin{array}{l}12 \\
89 \cdot 3 \\
10.5\end{array}$ & $\begin{array}{r}12 \\
102.5 \\
14.0\end{array}$ & $\begin{array}{l}10 \\
89.6 \\
10.0\end{array}$ & $\begin{array}{l}12 \\
2.01 \\
0.61\end{array}$ & $\begin{array}{c}12 \\
3.04 \\
0.67\end{array}$ & $\begin{array}{r}11 \\
101 \cdot 8 \\
20 \cdot 2\end{array}$ & $\begin{array}{l}12 \\
18.5 \\
2.8\end{array}$ & $\begin{array}{l}12 \\
0.51 \\
0.08\end{array}$ \\
\hline $\begin{array}{l}\text { Nonsmokers } \\
\text { n } \\
\text { 齐 }\end{array}$ & $\begin{array}{c}8 \\
64 \cdot 5 \\
1 \cdot 12\end{array}$ & $\begin{array}{c}8 \\
119 \cdot 2 \\
9 \cdot 4\end{array}$ & $\begin{array}{l}8 \\
26 \cdot 1 \\
10 \cdot 2\end{array}$ & $\begin{array}{c}8 \\
89 \cdot 5 \\
9 \cdot 62\end{array}$ & $\begin{array}{c}8 \\
103 \cdot 2 \\
15 \cdot 10\end{array}$ & $\begin{array}{l}8 \\
89.0 \\
11 \cdot 6\end{array}$ & $\begin{array}{l}8 \\
1.93 \\
0.44\end{array}$ & $\begin{array}{l}8 \\
3 \cdot 16 \\
0.63\end{array}$ & $\begin{array}{l}7 \\
97 \cdot 1 \\
22 \cdot 6\end{array}$ & $\begin{array}{c}8 \\
18.5 \\
2.9\end{array}$ & $\begin{array}{l}8 \\
0.51 \\
0.08\end{array}$ \\
\hline $\begin{array}{l}n \\
\overline{\mathbf{x}} \\
\mathbf{S D}\end{array}$ & $\begin{array}{c}4 \\
64 \cdot 0 \\
2 \cdot 1\end{array}$ & $\begin{array}{c}4 \\
126.8 \\
21.6\end{array}$ & $\begin{array}{c}4 \\
25 \cdot 2 \\
5 \cdot 3\end{array}$ & $\begin{array}{c}4 \\
89.2 \\
13.6\end{array}$ & $\begin{array}{c}4 \\
101 \cdot 0 \\
13.6\end{array}$ & 92 & $\begin{array}{l}4 \\
2 \cdot 18 \\
0.92\end{array}$ & $\begin{array}{l}4 \\
2.79 \\
0.76\end{array}$ & $\begin{array}{c}4 \\
110 \\
14 \cdot 3\end{array}$ & $\begin{array}{c}4 \\
18.7 \\
3 \cdot 0\end{array}$ & $\begin{array}{l}4 \\
0.51 \\
0.08\end{array}$ \\
\hline
\end{tabular}

1RAW = airway resistance.

'TGV = thoracic gas volume.

จVD = anatomic deadspace.

Denotes significant difference between nonsmokers and exsmokers $P<0.05$.

male exsmoking and the other groups or could represent a change related to their smoking habit.

\section{DISCUSSION}

It should be stated at the outset that the estimation of the effective diameter of the pulmonary airspaces using aerosols is fundamentally an anatomical measurement. It is hoped that the use of aerosols will permit an indirect measure of airspace dimensions which will not only make possible more realistic estimates of average airspace sizes in normal subjects, but will also allow an estimate of the variability of these sizes within a normal population.

We were somewhat surprised that in so far as aerosol persistence is an estimate of airspace diameter, this size did not correlate well with other predictors of lung size, such as height or lung volumes. We also found no good correlations between effective airspace diameters and age or sex. The observations may be explained partially on the basis of the relatively large dispersion of values for effective diameters that was seen between individuals which might obscure meaningful correlations. On the other hand, Green, Mead, and Turner (1974) found that maximal expiratory flows which are in part related to the geometry of the airways were also quite variable between different subjects with similar lung volumes. They postulated the concept of 'dysanaptic growth' of the two parts of the lungs, the central airways, and the peripheral gas exchange units, as an explanation for their findings.

We suppose that the standard lung function test that most closely resembles the aerosol test is the $\frac{O}{3}$ single breath carbon monoxide diffusing capacity (transfer factor). Even here, however, there are marked differences between the two measures. $\frac{D}{0}$ First, the gas molecules utilized in the transfer test are approximately 1000 times smaller than the aerosol particles and therefore their root mean $N$ square displacement should be approximately 1000 times greater than that of the aerosol ${ }^{\omega}$ particles. Secondly, the volumes inhaled in the two tests are several litres (one vital capacity) fore the gas and one litre for the aerosol. Thirdly, the gas is inhaled beginning at residual volume, whereas the aerosol is inhaled beginning at $1.2 \frac{0}{\circ}$ litres from total lung capacity. Thus, the gase would be expected to be distributed more or less? uniformly throughout the lungs in proportion too their relative regional ventilation, whereas the aerosol, being inhaled near total lung capacity, $\Omega$ 
should be distributed preferentially to the dependent lung zones that receive most of the latter part of the inspiratory volume (Milic-Emili et al., 1966.

Thus, while the aerosol technique would be expected to be markedly influenced by small differences in airways geometry, the transfer test would not.

The finding of widely different average airspace diameters among healthy subjects with similar lung volumes and, apparently, lung sizes has implications in the area of the pneumoconiosis-producing dusts. Given two subjects with similar lung volumes but one having smaller mean airspace diameters, both working in the same dusty environment, the one with the smaller airspaces might be expected to deposit more particles per unit of alveolar ventilation than the one with larger airspaces. Differences between individuals with regard to deposition during steady state breathing have been reported by a number of investigators at a variety of particle sizes (Altshuler et al., 1957; Lippman and Albert, 1969; Giacomelli-Maltoni et al., 1972). The situation is, however, much more complicated during active respiration than during the breath holding period considered here. This is because during steady state breathing experiments previously cited, much of the intersubject variation in aerosol deposition was accounted for on the basis of the differences in the amount of mixing between inhaled air containing aerosol and lung air. Therefore, the only way in which the effect of size of deep airspaces on deposition during steady state breathing could be determined would be to make both measurements on the same subjects; to our knowledge, this has not been done. It was because of this problem that we chose to use the breath holding method to make our estimates of airspace diameters.

Deposition of particles is only one part of the pneumoconiosis story. Another relates to the rate of clearance of the deposited particles, which has also been shown to have considerable intersubject variability (Albert et al., 1973).

Unfortunately, in many respects our experiments are of the 'black box' variety. The data obtained represent the calculated mean diameters for a considerable fraction of the lung and do not permit precise anatomical localizations. The great bulk of the $1000 \mathrm{ml}$ inhalation of aerosol-containing air would penetrate beyond the conducting airways into the gas exchanging alveolated airspaces. Our measurements are, therefore, weighted in favour of the small intrapulmonary airspaces where the mean linear distance a particle needs to travel to impact on a wall during breath holding is relatively short.

It should be noted that the volume of the aerosol inhaled was held constant; however the size of the anatomical deadspace varied from subject to subject, in those in whom it was measured. Thus, the relative fraction of the inhaled aerosol present within the small intrapulmonary airspaces varied inversely in relation to the size of the deadspace. This may have contributed to the dispersion of the values of the calculated airspace diameters within our subjects. The relatively high positive correlation between measured airspace diameters and anatomical deadspace found in female subjects $(r=0.71)$ appears to support this assumption. On the other hand, the mean relative fractions of inhaled aerosol that penetrated beyond the anatomical deadspace for the men and women were 0.86 and 0.90 respectively. It seems unlikely that a $4 \%$ difference between the fractions penetrating into the intrapulmonary airspaces could explain all of the differences found in diameters estimated by aerosol persistence.

The exact location of the aerosol at the beginning of breath holding is not known for another reason. Pathway lengths are not the same to all parts of the respiratory tract; therefore the anatomical region in which the aerosol is suspended may be different. There is bound to be some axial dispersion of the aerosol during inhalation owing to the fact that at these flow rates flow is laminar in most of the respiratory tract. On the other hand, the changes produced in $t \frac{1}{2}$ by increasing inhaled volume beyond $600 \mathrm{ml}$ were relatively small when studied by a bolus technique (Palmes et al., 1973) in six normal subjects. The t $\frac{1}{2}$ of aerosol persistence observed in subjects inhaling $1000 \mathrm{ml}$ would not be expected to be greatly influenced by this axial dispersion.

Recently, Engel et al. (1972) demonstrated that, due to cardiac churning, there is considerable mixing between alveolar gas and deadspace gas over and above that accounted for by molecular diffusion. If, as these authors suggest, convective mixing associated with nonrandom eddy currents and secondary motions is an important factor contributing to the spread of the gas front, it also could contribute to the dispersion of our aerosol during breath holding. This effect should have been relatively small, however, since the aerosol particles remaining airborne would be carried in the bulk flow of air produced by cardiac churning which, according to Engel's calculations, was 
equivalent to a tracheal flow of approximately $100 \mathrm{ml}$ per second.

The most straightforward procedure to establish the relationship between aerosol persistence during breath holding and the size of the airspaces is to study the same lungs using aerosol persistence and morphometric measurements on histological sections. This has obviously not been done on any of our subjects, but recently Matsuba and Thurlbeck (1971) measured the number and average diameters of small (less than $2 \mathrm{~mm}$ ) nonalveolated airways in the lungs of 20 normal cadavers after carefully controlled inflation, fixation, and sectioning. Figure 2 shows a cumulative frequency diagram comparing the results of Matsuba and Thurlbeck with the aerosol data on estimated airspace diameters. It can be seen that they found an average diameter of $0.68 \mathrm{~mm}$ and a coefficient of variation of $24 \%$, while our value for the average effective airspace diameter, as estimated by aerosol persistence, was $0.54 \mathrm{~mm}$ with a $21 \%$ coefficient of variation. We do not believe that a strict comparison of average sizes by the two methods is justified, because the aerosol method is looking at alveolated airspaces as well. Nevertheless the similarity of the coefficients of variation for the two sets of values, $24 \%$ versus $21 \%$, is highly suggestive that there is considerable variability in the average size of similar anatomical units in normal human populations when estimated by either technique.

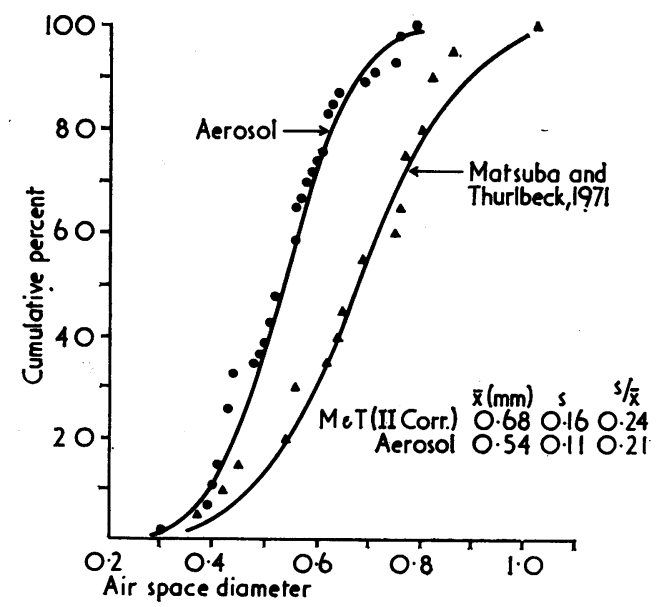

FIG. 2. Distribution of airspace diameters determined by aerosol persistence compared with diameters of small $(<2 \mathrm{~mm})$ nonalveolated airways found by Matsuba and Thurlbeck (1971). The ordinate refers to the percent of airspaces less than the stated diameter.
It should also be noted that previous investiga tions by Thurlbeck (1967), and more recent ones? by Angus and Thurlbeck (1972), on the number? and dimensions of alveoli in the normal human lung also suggest wide variations between subjects of similar heights. These workers found that ales though the total number of alveoli and, conse $-\overrightarrow{0}$ quently, lung volume were positively correlatedwith body length (height), the mean lineare intercept (average interalveolar distance) was independent of body length and lung volume. $x$

This type of distribution in normal populations $\omega$ has profound implications for lung models, whether one considers either gas transport and distribution or aerosol distribution and deposition ${ }_{0}^{\omega}$ Treating the airspace diameters as if they were approximately equal for all normal subjects makes it possible to arrive at elegant models for estimating aerodynamic characteristics, but the models fail to take into account variability ince airspace size within normal subjects and the dif or ference in aerosol behaviour which would resulti from this variability. One of the models for? aerosol deposition in wide use is that of the International Committee for Radiation Protec-0 tion (Morrow, 1966). This model is used too estimate total and regional aerosol deposition for each particle size in a single anatomical mode made up of tubes of a series of fixed sizes. Similarly, Weibel's regular model of the lungo (Weibel, 1973), which is also widely used to explain aerodynamic behaviour, certainly does noto suggest such wide variations in the anatomy of the airspaces between subjects as we or Matsubao and Thurlbeck (1971) have detected.

The New York University participation in this in vestigation was supported in part under Grants Nos. $\mathrm{OH} 00317$ and OH00396, National Institute for? Occupational Safety and Health, Public Health Ser vice, Department of Health, Education, and Welfare, and is part of a Center program supported by theू National Institute of Environmental Health Sciences̆ Grant No. ES00260.

We thank Drs. W. K. C. Morgan and N. Nelsonw for their valuable advice concerning the manuscript.

\section{REFERENCES}

Albert, R. E., Lippman, M., Peterson, H. T. Jr $\stackrel{\mathscr{\infty}}{;}$ Berger, J., Sanborn, K., and Bohning, D. (1973). Bronchial deposition and clearance of aerosols. Archives of Internal Medicine, 131, 115.

Altshuler, B., Yarmus, L., Palmes, E. D., and Nelson, N. (1957). Aerosol deposition in the human respiratory tract. I. Experimental procedures and total deposition. Archives of Industrial Health, 15, 293. 
Angus, G. E. and Thurlbeck, W. M. (1972). Number of alveoli in the human lung. Journal of Applied Physiology, 32, 483.

Dubois, A. B., Botelho, S. Y., Bedell, G. N., Marshall, R., and Comroe, J. H. (1956a). A rapid plethysmographic method for measuring thoracic gas volume: a comparison with a nitrogen washout method for measuring functional residual capacity in normal subjects. Journal of Clinical Investigation, 35, 322.

$\longrightarrow,-$, and Comroe, J. H. (1956b). A new method for measuring airway resistance in man using a body plethysmograph. Journal of Clinical Investigation, 35, 327.

Engel, L. A., Menkes, H., Wood, L. D. H., Utz, G., Joubert, J. and Macklem, P. T. (1972). Gas mixing during breath holding studied by intrapulmonary gas sampling. Journal of Applied Physiology, 35, 9.

Fowler, W. S. (1948). Lung function studies. II. The respiratory dead-space. American Journal of Physiology, 154, 405.

Giacomelli-Maltoni G., Melandri, C., Prodi, V., and Tarroni, G. (1972). Deposition efficiency of monodisperse particles in human respiratory tract. American Industrial Hygiene Association Journal, 33, 603.

Green, M., Mead, J., and Turner, J. M. (1974). Variability of maximum expiratory flow-volume curves. Journal of A pplied Physiology, 37, 67.

Hankinson, J. L. and Lapp, N. L. (1970). Time-pulse generator for flow-volume curves. Journal of Applied Physiology, 29, 109.

Kory, R. C., Callahan, R., Boren, H. G., and Syner, J. C. (1961). Clinical spirometry in normal men. American Journal of Medicine, 30, 243.

Smith, J. R., and Callahan, R. (1966). Quoted in: Gaensler, E. A., and Wright, G. W. (1966). Evaluation of respiratory impairment. Archives of Environmental Health, 12, 146.

Landahl, H. D. (1950). On the removal of airborne droplets by the human respiratory tract. I. The lung. Bulletin of Mathematical Biophysics, 12, 43.

Lippman, M. and Albert, R. E. (1969). The effect of particle size on the regional deposition of inhaled aerosols in the human respiratory tract. American Industrial Hygiene Association Journal, 30, 257.

Matsuba, K. and Thurlbeck, W. M. (1971). The number and dimensions of small airways in nonemphysematous lungs. American Review of Respiratory Disease, 104, 516.

Milic-Emili, J., Henderson, J. A. M., Dolovich, M. B., Trop, D., and Kaneko, K. (1966). Regional distribution of inspired gas in the lung. Journal of Applied Physiology, 21, 749.

Morrow, P. E. (Chairman) (1966). Report of task group on lung dynamics to ICRP. Deposition and retention models for internal dosimetry of the human respiratory tract. Health Physics, 12, 173.
Needham, C. D., Rogan, M. C., and McDonald, I. (1954). Normal standards for lung volumes, intrapulmonary gas-mixing, and maximum breathing capacity. Thorax, 9, 313.

Ogilvie, C. M., Forster, R. E., Blakemore, W. S., and Morton, J. W. (1957). A standardized breath holding technique for the clinical measurement of the diffusing capacity of the lung for carbon monoxide. Journal of Clinical Investigation, 36, 1 .

Palmes, E. D. (1973). Measurement of pulmonary air spaces using aerosols. Archives of Internal Medicine, 131, 76.

_- Altshuler, B., and Nelson, N. (1967). Deposition of aerosols in the human respiratory tract during breath holding. Inhaled Particles and Vapours II, edited by C. N. Davies, p. 339. Pergamon Press, London and New York.

, Goldring, R. M., Wang, C. S., and Altshuler, B. (1971). Effect of chronic obstructive pulmonary disease on rate of deposition of aerosols in the lung during breath holding. Inhaled Particles III, Vol. I, p. 123, edited by W. H. Walton. Unwin, Old Woking.

— and Wang, C. S. (1971). An aerosol inhalation apparatus for human single breath deposition studies. American Industrial Hygiene Association Journal, 32, 43.

,-- , Goldring, R. M., and Altshuler, B. (1973). Effect of depth of inhalation on aerosol persistence during breath holding. Journal of Applied Physiology, 34, 356.

Radford, E. P. (1955). Ventilation standards for use in artificial respiration. Journal of Applied Physiology, 7, 451.

Seaton, A. (1972). Pulmonary capillary blood volume in women: normal values and the effect of oral contraceptives. Thorax, 27, 75.

, Lapp, N. L., and Morgan, W. K. C. (1972). Relationship of pulmonary impairment in simple coal workers' pneumoconiosis to type of radiographic opacity. British Journal of Industrial Medicine, 29, 50.

Thurlbeck, W. M. (1967). The internal surface area of nonemphysematous lungs. American Review of Respiratory Disease, 95, 765 .

Wang, C. S., Altshuler, B., and Palmes, E. D. (1968). The distribution and deposition of particles suspended between parallel plane surfaces. Journal of Colloid and Interface Science, 26, 41.

Weibel, E. R. (1963). Morphometry of the Human Lung. Academic Press, New York, NY.

Requests for reprints to: Dr. N. LeRoy Lapp, M.D., Appalachian Laboratory for Occupational Respiratory Diseases, PO Box 4292, Morgantown, West Virginia 26505, USA. 